\title{
Duração da suplementação de ractopamina em dietas para leitoas em terminação mantidas sob alta temperatura ambiente
}

\author{
Duration of ractopamine supplementation in diets for finishing gilts maintained \\ under high temperature environment
}

\section{Elizangela Alves da Silva ${ }^{\mathrm{I}}$ Charles Kiefer ${ }^{\mathrm{II}}$ Mariana Souza de Moura ${ }^{\mathrm{I}}$ Silvano Bünzen ${ }^{\mathrm{II}}$ Alexandre Pereira dos Santos ${ }^{\mathrm{I}}$ Camilla Mendonça Silva $^{\mathrm{IV}}$ Clariana Leon Nantes $^{\mathrm{IV}}$}

\section{RESUMO}

\begin{abstract}
Este estudo foi realizado com o objetivo de avaliar a duração da suplementação de ractopamina na dieta de leitoas em terminação, mantidas sob alta temperatura ambiente. Foram utilizadas 48 leitoas com peso inicial de $70,4 \pm 2,6 \mathrm{~kg}$, distribuídas no delineamento de blocos ao acaso, com seis tratamentos (suplementação de ractopamina por 0 , $7,14,21,28$ e 35 dias pré-abate) e quatro repetições, sendo a unidade experimental constituída por dois animais. $O$ peso final e o consumo de ração diário não foram influenciados $(P>0,05)$ pelos tratamentos. $O$ ganho de peso aumentou e a conversão alimentar reduziu linearmente $(P<0,05)$ com o aumento do tempo de suplementação de ractopamina na dieta. As características quantitativas de carcaça (peso e rendimento de carcaça quente, espessura de toucinho, percentual de carne magra, profundidade de músculo e área de olho-de-lombo) $n \tilde{a} o$ foram influenciadas $(P>0,05)$ pela duração da suplementação de ractopamina na dieta. O peso dos pulmões, coração, fígado, rins e baço também não foi modificado $(P>0,05)$ pelos tratamentos. Concluiu-se que a inclusão de 20 ppm de ractopamina na dieta de leitoas em terminação, mantidas sob alta temperatura ambiente, durante 28 dias, maximiza a resposta de ganho de peso diário e, durante 35 dias, maximiza a resposta para conversão alimentar. Contudo, a inclusão do aditivo não altera as características quantitativas de carcaça e não afeta o desenvolvimento das vísceras.
\end{abstract}

Palavras-chave: aditivos, características de carcaça, desempenho, repartidor de energia.

\section{ABSTRACT}

The study was conducted to evaluate the duration of the supplementation of ractopamine in the diet of finishing gilts maintained under high temperature environment. Forty eight females, with initial weight of $70.4 \pm 2.6 \mathrm{~kg}$ were used. The pigs were distributed in randomized blocks design of six treatments (supplementation of ractopamine for 0, 7, 14, 21, 28 and 35 days pre-slaughter) and four replications, each experimental unit consisted of two animals. The final weight and daily feed intake were not affected $(P>0.05)$ by treatments. The weight gain increased and the feed conversion decreased linearly $(P<0.05)$ according to the increased length of supplementation of ractopamine in the diet. The quantitative characteristics of carcass (weight and hot carcass yield, backfat thickness, percentage of lean meat, depth of muscle and loin eye area) was not influenced $(P>0.05)$ by duration of supplementation of ractopamine in the diet. The weights of the lungs, heart, liver, kidneys and spleen were not modified $(P>0.05)$ by treatments. It was concluded that inclusion of 20 ppm of ractopamine in the diet of finishing gilts maintained under high temperature environment during 28 days maximizes the response of daily gain and during 35 days maximizes the response to feed conversion. However, the inclusion of the additive does not alter the quantitative characteristics of carcass and does not affect the development of the viscera.

Key words: additives, carcass characteristics, distribution of energy, performance.

\section{INTRODUÇÃO}

Tem-se constatado que alguns fatores podem influenciar a resposta dos suínos à ractopamina, dentre os quais estão a genética (BARK et al., 1992), o

'Programa de Pós-graduação em Ciência Animal, Universidade Federal de Mato Grosso do Sul (UFMS), 79074-460, Campo Grande, MS, Brasil.

"Departamento de Zootecnia, Universidade Federal de Santa Maria (UFSM), Campo Grande, MS, Brasil. E-mail: charles@ufms.br. Autor para correspondência.

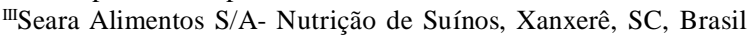

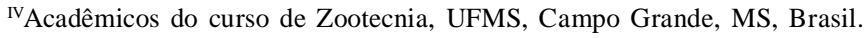


nível de inclusão de ractopamina (SANCHES et al., 2010a, b), os níveis de aminoácidos da dieta (MARINHO et al., 2007), o sexo (AMARAL, 2008) e o peso dos animais (CROME et al., 1996). O desempenho e as características de carcaça dos suínos também podem ser influenciados pela duração da suplementação de ractopamina na dieta, sendo que a máxima resposta tem sido obtida entre três (WILLIAMS et al., 1994) a cinco semanas de suplementação do aditivo (ARMSTRONG et al., 2004). Porém, na prática, tem-se recomendado a suplementação até quatro semanas, devido à redução das respostas em função do fenômeno chamado down-regulation ou dessensibilização dos receptores $\beta$-adrenérgicos (MOODY et al., 2000).

Além disso, é possível constatar que os suínos apresentam desempenho distinto quando submetidos a temperaturas ambientais de conforto e de estresse por calor, contudo a máxima resposta tem sido observada com o nível de 20ppm de ractopamina em ambas as condições térmicas (SANCHES et al., 2010a, b). Diante disso, são necessários novos estudos para estabelecer o tempo ideal de duração da inclusão de ractopamina na dieta dos suínos, quando submetidos a temperaturas ambientais elevadas, que são as predominantes no Brasil. Nesse contexto, realizou-se este estudo com o objetivo de avaliar a duração da inclusão de ractopamina em dietas para leitoas em terminação, mantidas sob alta temperatura ambiente.

\section{MATERIAL E MÉTODOS}

$\mathrm{O}$ experimento foi conduzido em câmara climática na Universidade Federal de Mato Grosso do Sul, Campo Grande/MS. Foram utilizadas 48 leitoas, Duroc/Pietran x Large White/Landrace, com peso inicial de 70,4 $\pm 2,6 \mathrm{~kg}$, distribuídas em delineamento de blocos ao acaso composto por seis tratamentos (suplementação de ractopamina por $0,7,14,21,28$ e 35 dias pré-abate) e quatro repetições, sendo a unidade experimental constituída por dois animais. Na formação dos blocos, foi levado em consideração o peso inicial dos animais.

Durante o período experimental, a temperatura e a umidade relativa do ambiente foram monitoradas diariamente às $8 \mathrm{~h}$ e $14 \mathrm{~h}$, por meio de um conjunto de termômetros de bulbo seco e bulbo úmido e de globo negro. Os valores registrados foram convertidos no índice de temperatura de globo e umidade (ITGU) para caracterizar o ambiente térmico em que os animais foram mantidos.

As dietas experimentais foram isonutritivas, preparadas à base de milho e farelo de soja (Tabela 1),
Tabela 1 - Composição percentual e nutricional das dietas experimentais.

\begin{tabular}{|c|c|c|}
\hline \multirow{2}{*}{ Ingredientes } & \multicolumn{2}{|c|}{ Ractopamina (ppm) } \\
\hline & 0 & 20 \\
\hline Milho & 71,847 & 71,847 \\
\hline Farelo de soja (45\%) & 25,230 & 25,230 \\
\hline Fosfato bicálcico & 0,784 & 0,784 \\
\hline Calcário & 0,546 & 0,546 \\
\hline Suplemento mineral ${ }^{1}$ & 0,050 & 0,050 \\
\hline Suplemento vitamínico ${ }^{2}$ & 0,400 & 0,400 \\
\hline Sal comum & 0,293 & 0,293 \\
\hline L-Lisina $\mathrm{HCl}$ & 0,420 & 0,420 \\
\hline DL-Metionina & 0,162 & 0,162 \\
\hline L-Treonina & 0,168 & 0,168 \\
\hline Ractopamina & 0,000 & 0,100 \\
\hline Caulim & 0,100 & 0,000 \\
\hline TOTAL & 100,00 & 100,00 \\
\hline Proteína bruta (\%) & 17,96 & 17,96 \\
\hline Energia metabolizável $\left(\mathrm{kcal} \mathrm{kg}^{-1}\right)$ & 3.230 & 3.230 \\
\hline Lisina total $(\%)$ & 1,232 & 1,232 \\
\hline Lisina digestível (\%) & 1,100 & 1,100 \\
\hline Metionina+cistina digestíveis (\%) & 0,682 & 0,682 \\
\hline Treonina digestível (\%) & 0,737 & 0,737 \\
\hline Triptofano digestível (\%) & 0,182 & 0,182 \\
\hline Valina digestível (\%) & 0,736 & 0,736 \\
\hline Cálcio (\%) & 0,484 & 0,484 \\
\hline Fósforo disponível (\%) & 0,248 & 0,248 \\
\hline Sódio (\%) & 0,160 & 0,160 \\
\hline
\end{tabular}

${ }^{1}$ Conteúdo por quilograma de produto: ferro, $100 \mathrm{~g}$; cobre, $10 \mathrm{~g}$; cobalto, 0,2g; manganês, 30g; zinco, $100 \mathrm{~g}$; iodo, 1,0g; selênio, $0,3 \mathrm{~g}$; excipiente q.s.p., $1000 \mathrm{~g}$.

${ }^{2}$ Conteúdo por quilograma de produto: Vitamina A, 6.000.000UI; Vitamina $\mathrm{D}_{3}, 1.000 .000 \mathrm{UI}$; Vitamina E, 12.000UI; Vitamina $\mathrm{B}_{1}$, $0,5 \mathrm{~g}$; Vitamina $\mathrm{B}_{2}, 2,6 \mathrm{~g}$; Vitamina $\mathrm{B}_{6}, 0,7 \mathrm{~g}$; ácido pantotênico, $10 \mathrm{~g}$; Vitamina $\mathrm{K}_{3}, 1,5 \mathrm{~g}$; ácido nicotínico, 22g; Vitamina B12, $0,015 \mathrm{~g}$; ácido fólico, 0,2g; biotina, $0,05 \mathrm{~g}$; colina, $100 \mathrm{~g}$; excipiente q.s.p., $1000 \mathrm{~g}$.

formuladas para suplantar os níveis nutricionais recomendados por ROSTAGNO et al. (2005). O nível de inclusão de ractopamina na dieta foi de 20ppm, visando a maximizar as respostas de desempenho e de características de carcaça, conforme estabelecido por SANCHES et al. (2010ab). A ractopamina foi inclusa na dieta em substituição ao caulim. As rações e a água foram fornecidas à vontade aos animais. A cada intervalo de sete dias, foi realizada a substituição da dieta sem ractopamina pela dieta contendo ractopamina, em função dos tratamentos experimentais. A cada troca, foram pesadas as sobras de ração dos comedouros e os resíduos de ração do chão para a determinação do consumo.

A pesagem dos animais ocorreu no início e no final do experimento, visando à obtenção de dados 
relativos ao ganho de peso e a conversão alimentar. O experimento teve duração de 35 dias e, ao seu término, os animais foram transportados para o frigorífico, onde foram alojados em baias de espera e submetidos a jejum de sólidos por $12 \mathrm{~h}$. Após o jejum e previamente ao abate, os animais foram pesados para determinar o rendimento de carcaça.

Foi realizado um corte na metade esquerda da carcaça, no ponto $\mathrm{P}_{2}$, visando à exposição do músculo Longissimus dorsi. Posteriormente, o músculo foi desenhado para a determinação da área de olho-delombo. Aárea foi determinada utilizando-se a contagem dos pontos, sendo que cada ponto representou uma área de $0,25 \mathrm{~cm}^{2}$. O percentual de carne magra foi determinado por meio da equação proposta por BRIDI \& SILVA (2007): rendimento de carne $(\%)=60-$ (espessura de toucinho x 0,58$)+$ (profundidade de músculo x 0,10 ).

Os dados foram submetidos à análise de variância pelo procedimento ANOVA do programa estatístico SAS (2001), sendo os graus de liberdade para a duração da suplementação de ractopamina desdobrados em polinômios ortogonais e as estimativas do período de duração da suplementação determinadas por meio de análises de regressão, ao nível de 5\% de significância.

\section{RESULTADOS E DISCUSSÃO}

A temperatura média do ar registrada na câmara climática foi de $28,7 \pm 1,3^{\circ} \mathrm{C}$, a umidade relativa de $87,6 \pm 6,8 \%$, a temperatura de globo negro de $30,0 \pm 1,1^{\circ} \mathrm{C}$ e o ITGU calculado em $80,6 \pm 1,6$. Considerando que a temperatura e a umidade relativa do ar críticas para essa categoria são, respectivamente, $27^{\circ} \mathrm{Ce} 90 \%$ (SAMPAIO et al., 2004), pode-se inferir que os animais foram submetidos a temperaturas ambientais elevadas durante a execução da pesquisa. Por sua vez, o ITGU calculado foi similar àquele de 81,0 , obtido por
ORLANDO et al. (2007) em pesquisa com suínos submetidos a altas temperaturas ambientais.

A inclusão de ractopamina na dieta não influenciou $(\mathrm{P}>0,05)$ o peso final dos animais e o consumo de ração diário (Tabela 2). O resultado obtido para o consumo de ração é corroborado por vários estudos com ractopamina (DUNSHEA et al., 1993a; MARINHO et al., 2007; MORAES et al., 2010; SANCHES et al., 2010a, b), nos quais não foram observados efeitos sobre essa variável. Os resultados nos estudos citados podem ser um indicativo de que a ractopamina não apresenta ação específica sobre o controle voluntário da ingestão de alimento nos suínos.

Por outro lado, os tratamentos influenciaram as demais variáveis de desempenho, indicando que o aumento do tempo de inclusão de ractopamina na dieta proporcionou aumentolinear do ganho de peso diário $(\mathrm{P}<0,01)$ e redução linear da conversão alimentar $(\mathrm{P}<0,01)$ das leitoas, segundo as equações: $\mathrm{GPD}\left(\mathrm{kg} \mathrm{d}^{-1}\right)=0,6735+0,00514 \mathrm{x}, \mathrm{R}^{2}=0,46 \mathrm{e}$ CA $\quad\left(\mathrm{kg} \mathrm{kg}^{-1}\right)=2,57589-0,01275 \mathrm{x}, \quad \mathrm{R}^{2}=0,47$, respectivamente.

De acordo com os resultados, pode-se inferir que a inclusão de 20ppm de ractopamina na dieta, durante 35 dias, proporcionou aumento de $29,7 \%$ do ganho de peso diário das leitoas em relação ao grupo que não consumiu o aditivo. Embora a análise estatística aponte aumento linear do ganho de peso diário, a diferença numérica dessa variável é muito pequena, quando se compara a inclusão de ractopamina na dieta durante 35 dias em relação à inclusão por 28 dias. Contudo, essa variável não apresentou efeito significativo quando testada pelo modelo descontínuo linear response plateau. Essa resposta nos permite inferir que a inclusão de ractopamina na dieta durante 28 dias foi adequada para maximizar o ganho de peso das leitoas.

Por sua vez, a suplementação de 20ppm de ractopamina durante 35 dias resultou em melhora de 19,8\% na conversão alimentar das fêmeas, quando

Tabela 2 - Desempenho de leitoas em terminação, suplementadas com ractopamina durante 0, 7, 14, 21, 28 e 35 dias.

\begin{tabular}{|c|c|c|c|c|c|c|c|c|}
\hline \multirow{2}{*}{ Variáveis } & \multicolumn{6}{|c|}{ - Duração da suplementação (dias) - } & \multirow{2}{*}{$<\mathrm{P}$} & \multirow[t]{2}{*}{$\mathrm{CV} \%$} \\
\hline & 0 & 7 & 14 & 21 & 28 & 35 & & \\
\hline Peso inicial $(\mathrm{kg})$ & 69,9 & 69,6 & 69,4 & 69,1 & 68,5 & 68,5 & 0,90 & 4,84 \\
\hline Peso final $\left(\mathrm{kg}^{*}\right)$ & 93,5 & 95,1 & 96,7 & 94,7 & 97,6 & 97,6 & 0,07 & 3,59 \\
\hline Ganho de peso diário $(\mathrm{kg} * *)$ & 0,64 & 0,73 & 0,78 & 0,77 & 0,83 & 0,83 & 0,01 & 14,28 \\
\hline Consumo de ração diário $(\mathrm{kg})$ & 1,71 & 1,73 & 1,83 & 1,63 & 1,86 & 1,76 & 0,55 & 12,69 \\
\hline Conversão alimentar** & 2,68 & 2,39 & 2,36 & 2,28 & 2,26 & 2,15 & 0,01 & 10,96 \\
\hline
\end{tabular}

*Efeito linear $(\mathrm{P}<0,07)$; **Efeito linear $(\mathrm{P}<0,01)$.

Ciência Rural, v.41, n.2, fev, 2011. 
comparado ao grupo controle não suplementado. Por sua vez, MIMBS et al. (2005) não observaram efeito da suplementação de 10ppm de ractopamina aos 7, 14, 21 e 28 dias de experimento sobre o peso final dos suínos, mas o aditivo melhorou a eficiência de utilização dos nutrientes da dieta, quando suplementado na dieta durante 21 e 28 dias. De forma similar, CARR et al. (2005), ao avaliarem a suplementação de 10ppm de ractopamina, não observaram efeito sobre o peso final dos animais, contudo os suínos suplementados durante 14 e 28 dias apresentaram melhora da eficiência alimentar em relação aos não suplementados no período.

Os efeitos positivos observados sobre o ganho de peso e a conversão alimentar neste estudo podem ser explicados pela melhor eficiência de utilização dos nutrientes das dietas, devido ao efeito da ractopamina sobre o metabolismo dos suínos, proporcionando aumento da síntese protéica e bloqueio parcial da lipogênese, favorecendo o aumento do ganho de peso e a melhora da conversão alimentar (SCHINCKEL et al., 2003). Essa hipótese é confirmada em estudo realizado por LATORRE et al. (2008), em que constataram correlação alta e positiva entre ganho diário em proteína e conversão alimentar, indicando que suínos com alta taxa de ganho de tecido protéico apresentam melhor eficiência alimentar. Além disso, essa proposição também pode ser justificada pelo fato de que a deposição de tecido protéico agrega mais moléculas de água $(1: 3,4)$, em relação à deposição de lipídios na carcaça (HALAS et al., 2010), resultando na melhora tanto do ganho em peso quanto da eficiência alimentar.
Não foi observado efeito $(\mathrm{P}>0,05)$ da duração da inclusão de ractopamina na dieta sobre as características quantitativas de carcaça das leitoas (Tabela 3). Resultado similar foi obtido por DUNSHEA et al. (1993a), que avaliaram a suplementação de 20ppm de ractopamina na dieta de leitoas durante seis semanas e não constataram efeito sobre o percentual de gordura e proteína na carcaça. Todavia, o resultado obtido difere da grande maioria das pesquisas com ractopamina, as quais demonstram aumento no rendimento de carcaça (ARMSTRONG et al., 2004), redução da espessura de toucinho e aumentos da profundidade de músculo e do percentual de carne magra da carcaça (MARINHO et al., 2007; PEREIRA et al., 2008).

Uma explicação provável para a não obtenção de efeitos positivos sobre as características quantitativas de carcaça a partir do aumento da duração da suplementação de ractopamina na dieta pode estar relacionada a fatores como a faixa de peso e ao sexo dos animais utilizados neste estudo. A partir de comparações, podemos constatar que a faixa de peso dos animais utilizados na realização deste trabalho está abaixo da faixa de peso dos animais em diversos estudos (CARR et al., 2005; MIMBS et al., 2005; MARINHO et al., 2007; PEREIRA et al., 2008), nos quais os pesquisadores constataram efeito da suplementação de ractopamina na dieta sobre as características de carcaça. Essa hipótese também é corroborada pelos resultados da pesquisa realizada por CROME et al. (1996), na qual constataram que a ractopamina foi mais eficaz em melhorar o desempenho e as características de carcaça quando administrada a suínos pesados (85 aos $125 \mathrm{~kg}$ ) em relação aos leves (68 aos 107kg). Nos

Tabela 3 - Características de carcaça e peso de vísceras de leitoas em terminação, suplementadas com ractopamina durante 0, 7, 14, 21, 28 e 35 dias.

\begin{tabular}{|c|c|c|c|c|c|c|c|c|}
\hline \multirow{2}{*}{ Variáveis } & \multicolumn{6}{|c|}{ - } & \multirow[t]{2}{*}{$<\mathrm{P}$} & \multirow[t]{2}{*}{$\mathrm{CV} \%$} \\
\hline & 0 & 7 & 14 & 21 & 28 & 35 & & \\
\hline \multicolumn{9}{|c|}{ - } \\
\hline Peso de carcaça $(\mathrm{kg})$ & 75,13 & 75,95 & 78,75 & 74,80 & 78,25 & 78,38 & 0,15 & 4,07 \\
\hline Rendimento de carcaça (\%) & 83,06 & 82,46 & 83,64 & 81,77 & 82,53 & 82,99 & 0,82 & 2,10 \\
\hline Espessura de toucinho (mm) & 8,0 & 6,0 & 7,0 & 6,0 & 5,0 & 7,0 & 0,58 & 19,16 \\
\hline Profundidade de músculo (mm) & 68,0 & 66,0 & 70,0 & 75,0 & 65,0 & 66,0 & 0,87 & 9,07 \\
\hline Carne magra $(\%)$ & 62,43 & 63,22 & 63,18 & 64,31 & 63,63 & 62,54 & 0,65 & 2,41 \\
\hline Área de olho-de-lombo $\left(\mathrm{cm}^{2}\right)$ & 46,14 & 49,03 & 50,90 & 56,34 & 51,08 & 52,94 & 0,10 & 12,59 \\
\hline Fígado (g) & 1.638 & 1.785 & $\begin{array}{c}\text { Vísceras } \\
1.636\end{array}$ & 1.670 & 1.681 & 1.746 & 0,91 & 13,27 \\
\hline Rins (g) & 339 & 342 & 381 & 342 & 357 & 380 & 0,66 & 13,50 \\
\hline Coração (g) & 320 & 348 & 321 & 387 & 333 & 357 & 0,65 & 18,00 \\
\hline Pulmões (g) & 693 & 681 & 638 & 733 & 701 & 710 & 0,81 & 22,82 \\
\hline Baço (g) & 169 & 160 & 148 & 167 & 167 & 162 & 0,71 & 12,40 \\
\hline
\end{tabular}


suínos mais pesados, a deposição de lipídios na carcaça tende a aumentar numa proporção maior em relação à deposição de proteína (WHITTEMORE, 1998), fato que pode aumentar a eficiência de ação da ractopamina em bloquear parcialmente a lipogênese.

O sexo dos animais utilizados neste trabalho também pode ter contribuído para a não obtenção de respostas positivas sobre as características quantitativas de carcaça, em função do aumento da duração da suplementação de ractopamina na dieta. Estudos têm evidenciado que a resposta da ractopamina sobre as características quantitativas da carcaça são mais pronunciadas nos suínos machos castrados em relação às fêmeas e aos machos inteiros (DUNSHEA et al., 1993b).

A duração da suplementação de ractopamina na dieta também não modificou $(\mathrm{P}>0,05) \mathrm{o}$ peso de fígado, coração, pulmões, rins e baço das leitoas (Tabela 3). Em geral, os resultados dos estudos não têm evidenciado efeitos da suplementação de ractopamina sobre o peso de vísceras (DUNSHEA et al., 1993b). Entretanto, trabalhos (SANCHES et al., 2010b) relatam redução do peso de fígado quando os suínos são suplementados com ractopamina. Segundo YEN et al. (1991), o efeito da ractopamina sobre a redução do peso dos órgãos do trato gastrintestinal pode estar relacionado à redução do consumo de ração, promovida pela ractopamina. Nesse sentido, em situações em que a ractopamina não altere o consumo de ração, provavelmente também não ocorrerá efeitos sobre o peso dos órgãos.

\section{CONCLUSÃO}

A inclusão de 20ppm de ractopamina na dieta de leitoas em terminação, mantidas sob alta temperatura ambiente, durante 28 dias, maximiza a resposta de ganho de peso diário e, durante 35 dias, maximiza a resposta para conversão alimentar. Contudo, a inclusão do aditivo não altera as características quantitativas de carcaça e não afeta o desenvolvimento das vísceras.

\section{REFERÊNCIAS}

AMARAL, N.O. Ractopamina hidroclorada em rações formuladas para suínos machos castrados ou para fêmeas, dos 90 aos $130 \mathrm{~kg}$. 2008. 48f.:il. Dissertação (Mestrado em Zootecnia) - Lavras: Universidade Federal de Lavras, MG.

ARMSTRONG, T.A. et al. The effect of dietary ractopamina concentration and duration of feeding on growth performance, carcass characteristics and meat quality of finishing pig. Journal of Animal Science, v.82, p.3245-3253, 2004. Disponível em: <http://jas.fass.org/cgi/reprint/82/11/3245>. Acesso em: 5 abr. 2010.
BARK, L.J. et al. Influence of genetic capacity for lean tissue growth on rate and efficiency of tissue accretion in pigs fed ractopamine. Journal of Animal Science, v.70, p.33913400, 1992. Disponível em: <http://www.animal-science.org/ cgi/reprint/70/11/3391>. Acesso em: 20 mar. 2010.

BRIDI, A.M.; SILVA, C.A. Métodos de avaliação de carcaça e da carne suína. Londrina: Midiograf, 2007. 97p.

CARR, S.N. et al. Effects of different cereal grains and ractopamine hydrochloride on performance, carcass characteristics, and fat quality in late-finishing pigs. Journal of Animal Science, v.83, p.223-230, 2005. Disponível em: <http://jas.fass.org/cgi/reprint/ 83/1/223>. Acesso em: 20 nov. 2009.

CROME, P.K. et al. Effect of ractopamine on growth performance, carcass composition, and cutting yields of pigs slaughtered at 107 and 125 kilograms. Journal of Animal Science, v.74, p.709-716, 1996. Disponível em: <http:// jas.fass.org/cgi/reprint/74/4/709>. Acesso em: 10 mar. 2010.

DUNSHEA, F.R. et al. Interrelationships between dietary protein and ractopamine on protein and lipid deposition in finishing gilts. Journal of Animal Science, v.71, n.11, 29312941, 1993a. Disponível em: <http://jas.fass.org/cgi/reprint/ 71/11/2931>. Acesso em: 10 mar. 2010.

DUNSHEA, F.R. et al. Interrelationships between sex and ractopamine on protein and lipid deposition in rapidly growing pigs. Journal of Animal Science, v.71, n.11, p.2919-2930, 1993b. Disponível em: <http://www.animal-science.org/cgi/ reprint/71/11/2919>. Acesso em: 20 nov. 2009.

HALAS, V. et al. Efficiency of fat deposition from non-starch polysaccharides, starch and unsaturated fat in pigs. British Journal of Nutrition, v.103, p.123-133, 2010. Disponível em: <http://journals.cambridge.org/download.php? file $=\% 2 \mathrm{FBJN} \% 2$ F B J N $10301 \% 2$ F S 0007114509991449 a . pdf \&code $=36 \mathrm{fbe} 7 \mathrm{c} 3 \mathrm{eddc} 27 \mathrm{c} 61 \mathrm{~d} 84 \mathrm{a} 553 \mathrm{e} 6 \mathrm{~b} 92 \mathrm{ef} 1>$. Acesso em: 20 abr. 2010. doi: 10.1017/S0007114509991449.

HERR, C.T. et al. Effect of nutritional level while feeding Paylean to late-finishing pigs. Purdue University Swine Day Report, p.89-95, 2000. Disponível em: <http://www.ansc.purdue.edu/ swine/swineday/sday00/16.pdf $>$. Acesso em: 20 mar. 2010.

LATORRE, M.A. et al. The relationship within and between production performance and meat quality characteristics in pigs form three different genetic lines. Livestock Science, v.115, p.258-267, 2008. Disponível em: <http://www.livestockscience.com/ article/S1871-1413(07)00439-8>. Acesso em: 20 mar. 2010. doi: 10.1016/j.livsci.2007.08.013.

MARINHO, P.C. et al. Efeito da ractopamina e de métodos de formulação de dietas sobre o desempenho e as características de carcaça de suínos machos castrados em terminação. Revista Brasileira de Zootecnia, v.36, p.1061-1068, 2007. Disponível em: <http://www.scielo.br/pdf/rbz/v36n4s0/11.pdf>. Acesso em: 20 mar. 2010. doi: 10.1590/S1516-35982007000500011.

MIMBS, K.J. et al. Effects of ractopamine on performance and composition of pigs phenotypically sorted into fat and lean groups. Journal of Animal Science, v.83, p.13611369, 2005. Disponível em: <http://jas.fass.org/cgi/reprint/ 83/6/1361>. Acesso em: 20 nov. 2009. 
MOODY, D.E. et al. Phenethanolamine repartitioning agents. In: D'MELLO, J.P.F. Farm animal metabolism and nutrition. Edinburg: CABI, 2000. p.65-95.

MORAES, E. et al. Ractopamina em dietas para suínos machos imunocastrados, castrados e fêmeas. Ciência Rural, v.40, n.2, p.409-414, 2010. Disponível em: <http://www.scielo.br/ pdf/cr/v40n2/a473cr1765.pdf $>$. Acesso em: 20 mar. 2010. doi: 10.1590/S0103-84782010000200023.

ORLANDO, U.A.D. et al. Níveis de proteína bruta e suplementação de aminoácidos em dietas para leitoas mantidas em ambiente de alta temperatura dos 60 aos $100 \mathrm{~kg}$. Revista Brasileira de Zootecnia, v.36, n.4, p.1069-1075, 2007. (supl.). Disponível em: <http://www.scielo.br/pdf/\%0D/rbz/ v36n4s0/12.pdf>. Acesso em: 20 mar. 2010. doi: 10.1590/ S1516-35982007000500012.

PEREIRA, F.A. et al. Efeitos da ractopamina e de dois níveis de lisina digestível na dieta sobre o desempenho e características de carcaça de leitoas em terminação. Arquivo Brasileiro de Medicina Veterinária e Zootecnia, v.60, p.943-952, 2008. Disponível em: 〈http://www.scielo.br/pdf/abmvz/v60n4/25.pdf>. Acesso em: 20 mar. 2010. doi: 10.1590/S0102-09352008000400025.

ROSTAGNO, H.S. et al. Tabelas brasileiras para aves e suínos. Composição de alimentos e exigências nutricionais. 2.ed. Viçosa: UFV, 2005. 186p.

SAMPAIO, C.A.P. et al. Avaliação do ambiente térmico em instalações para crescimento e terminação de suínos utilizando os índices de conforto térmico nas condições tropicais. Ciência Rural, v.34, p.785-790, 2004. Disponível em: <http:// www.scielo.br/pdf/cr/v34n3/a20v34n3.pdf>. Acesso em: 20 nov. 2009. doi: 10.1590/S0103-84782004000300020.
SANCHES, J.F. et al. Níveis de ractopamina para suínos machos castrados em terminação e mantidos sob conforto térmico. Ciência Rural, v.40, p.403-408, 2010a. Disponível em: <http://www.scielo.br/pdf/cr/v40n2/a441cr1445.pdf>. Acesso em: 10 jun. 2010. doi: 10.1590/S0103-84782009005000257.

SANCHES, J.F. et al. Níveis de ractopamina para suínos machos castrados em terminação mantidos sob estresse por calor. Revista Brasileira de Zootecnia, v.39, p.1523-1529, 2010b. Disponível em: <http://www.scielo.br/pdf/rbz/v39n7/a19v39n7.pdf>. Acesso em: 10 jun. 2010. doi: 10.1590/S1516-35982010000700019.

SCHINCKEL, A.P. et al. Development of a model to describe the compositional growth and dietary lysine requirements of pigs fed ractopamine. Journal of Animal Science, v.81, p.1106-1119, 2003. Disponível em: <http://www.animalscience.org/cgi/reprint/81/5/1106>. Acesso em: 20 mar. 2010.

SAS - STATISTICAL ANALYSES SYSTEM. SAS/STAT software, version 8.02. Cary, 2001. $1686 \mathrm{p}$.

WHITTEMORE, C. The science and practice of pig production. 2.ed. London, UK: Blackwell Science. 1998. $624 \mathrm{p}$.

WILLIAMS, N.H. et al. The impact of ractopamine, energy intake, and dietary fat on finisher pig growth performance and carcass merit. Journal of Animal Science, v.72, p.31523162, 1994. Disponível em: <http://jas.fass.org/cgi/reprint/ 72/12/3152>. Acesso em: 20 mar. 2010.

YEN, T. et al. Effect of ractopamine on growth, carcass traits, and fasting heat production of U.S. contemporary and crossbred and chinese meishan pigs. Journal of Animal Science, v.69, p.4810-4822, 1991. Disponível em: <http://jas.fass.org/cgi/ reprint/69/12/4810>. Acesso: 20 mar. 2010. 